\title{
通氣法による揮発性塩基定量に関寸る研究-IV. 溜出速度恒数を左右する特殊因子（其の2）
}

\author{
河 端 俊 治 \\ （国立予防衛生研究所）
}

Fundamental Studies on the Determination of Volatile Basic

Nitrogen by Aeration Method-IV. Special Factors Affecting

the Velocity Constant in Removing the Volatile Dase (2)

Toshiharu Kawabata

Continuing from the previous paper, this paper deals with a study of some factors affecting the velocity constant in removing the volatile base by aeration method, with special reference to the freshness of the fish meat examined. Results obtained are as follows:

1. The fresh meat of several species of fish, showed no difference in the velocity constant, while some of them showed a considerable difference in the velocity constant when spoiled. The curves of volatile base obtained were not of complete agreement with the first order reaction. The cause of this error was found to be due to the high content of trimethylaminoxide in the muscle.

On the other hand, the curves obtained from the samples of spoiled fish meat which have relatively small amount or no oxide, such as albacore, mackerel, carp and whale meat, were found to present the curves mearly or completely in agreement with the theoretical curves.

2. A shortened procedure was presented, which is based on obtaining a 50 per cent removal of total volatile base and is able to determine within a short period of 15 minutes aerating at $45^{\circ} \mathrm{C}, 50 \mathrm{l} / \mathrm{hr}$.

\section{ま え がき}

通気法は減壬法に較べ珐置や操作は簡易ではあるが著しく測定に特間がかかる。之を短樎するには，温度 を高めるのが最も炀率がよいが，著者等”が既に報告したよ 塩基の增加方見られるので不都合である。クジラ肉ては $80^{\circ} \mathrm{C}$ でる二次的塩基の生成が認められない2と

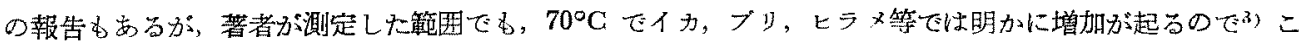
の上ろな高温で測定を行ろことは普遍的方法としては好適とは思われない。夯に通気量を堌すことす考光ら えるが，之亦既に報告した通り速度恒数（K）と一次式の関係にあり，之に条り多くの期待をかけることは 效率の点から良港ではない。更に通気量を增加すれば発泡の度がひどくなつたり，Aeration tube 中の試料 や，受器の酸液が飛散する扢それも生じ，且一定に保持することが困難になる。著者は，既に報告した塩基

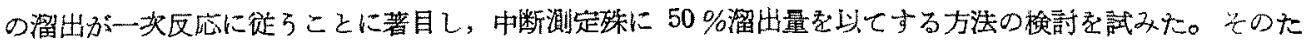

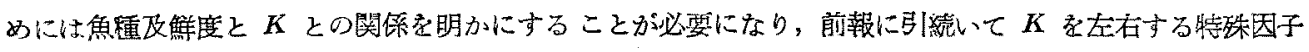

1952 年 10 月 14 日受理 
$8 \cdot 20$

について研究圭行つた。

\section{実 験 及考察}

\section{1. 新鮮奥肉地壏基の溜出速度}

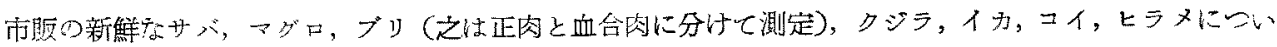

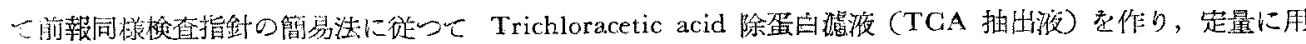

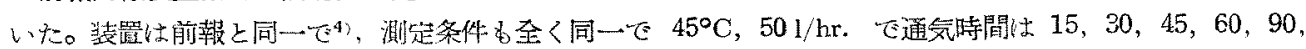

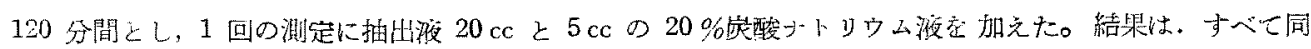

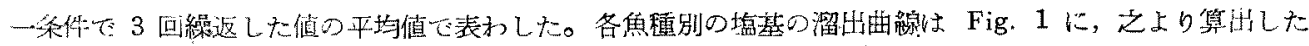
$N_{0}$ (終局量)とKは Table 1 に示した。

Table 1. The velocity constant in removing volatile base

(1. Fresh and spoiled fich meat extract)

\begin{tabular}{|c|c|c|c|c|}
\hline \multirow[b]{2}{*}{ Specis } & \multicolumn{2}{|c|}{ Fresh meat } & \multicolumn{2}{|c|}{ Spoiled meat } \\
\hline & $\operatorname{mg} N^{N} 20 \mathrm{cc}$ & $K$ & $\operatorname{mg} N / 20 \mathrm{cc}$ & $K$ \\
\hline Scontor jatponicus Houtluyn-mackerel & 0.764 & 2.36 & 2.78 & 2.61 \\
\hline Thunnus orientalis-albacore & 0.768 & 2.40 & 0.632 & 2.63 \\
\hline Seriola quindueradiata Temminck \& Schlegel & 0.622 & 2.26 & 0.659 & 2.53 \\
\hline$" \quad$ " $\quad$ (dark muscle) & 0.634 & 2.34 & - & - \\
\hline Whale (species name unknown) & 0.584 & 2.55 & 1.14 & 2.69 \\
\hline Loligo edulis Hoyle-cuttlefish & 0.474 & 2.59 & 2.84 & 2.69 \\
\hline Paraichthys oitvaceus (T. \& S.) flatfish & 0.264 & 2.51 & 1.92 & 2.68 \\
\hline Cyprinus carpio Linnk-carp & 0.384 & 2.25 & 1. 46 & 2.31 \\
\hline
\end{tabular}

矢の結果 $K=2.41 \pm 0.121$ そなつたが,ここで,こ

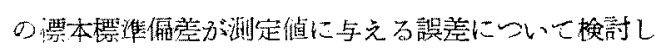
た。即ち，特に初澌腐敗前後圭刘象とし， $N_{0} \not 520$, $30,40 \mathrm{mg} \%$ をあつた特, $t$ が 1.5 (90分) 及 2 (120 分)に抬け方㨨出量 $(N)$ 妾計算に上り求めた。ここ で $K$ の上限 $K_{1}=2.41+0.121=2.53$, 下限 $K_{y}=$ $2.41-0.12=2.29$ とし，第 1 報にて記䨖した式に代入 して $N$ 学算持した結果が Table 2 にて示してあか。

Table 2 Influence of the variance in $K$ upon the recoviry of volatile base (Fresh fish meat) $K_{(\ell y)}=2.41 \pm 0.121$

$k^{\prime}=2.41+0.121=2.53$ (upper range) $k_{:}=3.41-0.121=2.29$ (lower range)

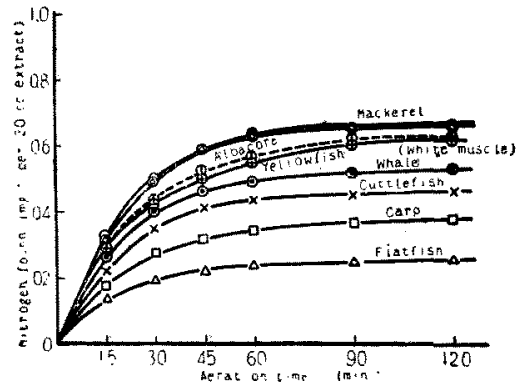

Fig. 1. Rate in removing the volatile base of fresh fish meat

\begin{tabular}{|c|c|c|c|c|}
\hline \multirow{3}{*}{$\begin{array}{l}N_{0} \text { (Total volatile tase) } \\
\mathrm{mg} . \quad N \text { in } 100 \mathrm{~g} \text { meat }\end{array}$} & \multicolumn{4}{|c|}{ Calculated Nitrogen content $(\mathrm{mg} \%)$ and recovery $(\%)$} \\
\hline & \multicolumn{2}{|c|}{$t_{1}=1.5(90 \mathrm{~min})}$. & \multicolumn{2}{|c|}{$t_{2}=2(120 \mathrm{~min})}$. \\
\hline & $k_{1}=2.53$ & $k_{2}=2.29$ & $k_{1}=2.53$ & $k_{2}=2.29$ \\
\hline 20 & $\begin{array}{l}19.6 \mathrm{mg} \% \\
(98 \%)\end{array}$ & $\begin{array}{l}19.4 \mathrm{mg} \% \\
(9 \% \%)\end{array}$ & $\begin{array}{l}19.9 \mathrm{mg} \% \\
(99.7 \%)\end{array}$ & $\begin{array}{l}19.8 \mathrm{mg} \% \\
(99 \%)\end{array}$ \\
\hline 30 & $\begin{array}{l}29.3 \\
(97.7)\end{array}$ & $\begin{array}{l}29.0 \\
(96.7)\end{array}$ & $\begin{array}{l}29.8 \\
(99.4)\end{array}$ & $\begin{array}{l}29.7 \\
(99.1)\end{array}$ \\
\hline 40 & $\begin{array}{l}39.1 \\
(98)\end{array}$ & $\begin{array}{l}38.7 \\
(97)\end{array}$ & $\begin{array}{l}39.4 \\
(99.3)\end{array}$ & $\begin{array}{l}39.6 \\
(99)\end{array}$ \\
\hline
\end{tabular}




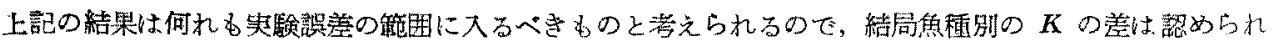

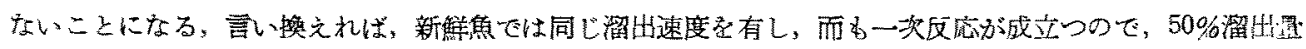
に上る中断測定が一応可能上云うことになる。

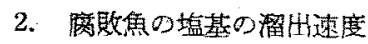

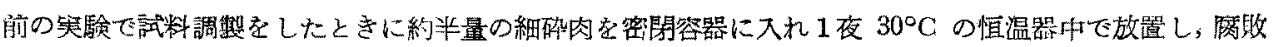

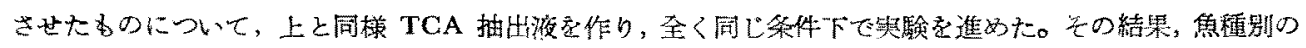
溜出曲線は Fig. 2 に記載し，又之より算代した $\mathrm{N}_{0}$ と $K$ の値は新焦魚と同じ Table 1 にのせた。

既に，第 2 報で報告した上うに，豚敗焦ては 40 分 以前の通気では $K$ の值が大きく第ることが出るので, 今回敗肉について求めた $K$ 名 45 分以降け $N$ 上り 計算しその平均值で表わした。このようにして求かた

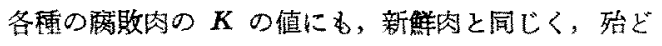
等しいことが判つた。ただここで注目されるのは，魚 種によつてはその溜出が必ずしる一次反応住わない おのあるるとで, 之を確めるために，Table 1 の右 欄の $K$ 及 $N_{0}$ の值より，各時間について理諭的な濯 H量 (一次反忘としての) 素求めた。その值は Fig. 2 の各曲線中に点總て园示しておいた。点線の画かれ ていない曲線士理論值と実測值が一致した場合でこ のようなるの山正しく一次反広に従つていることを意 制する。著者の調べた範围で，大きな不一致を示した るのにはイカ、ヒラメがあり,サバ,ブリては極く萁 かな差があつたが、コイ、、グロ，クジラでは，一次 反応の曲線には榿めて良く一致した。

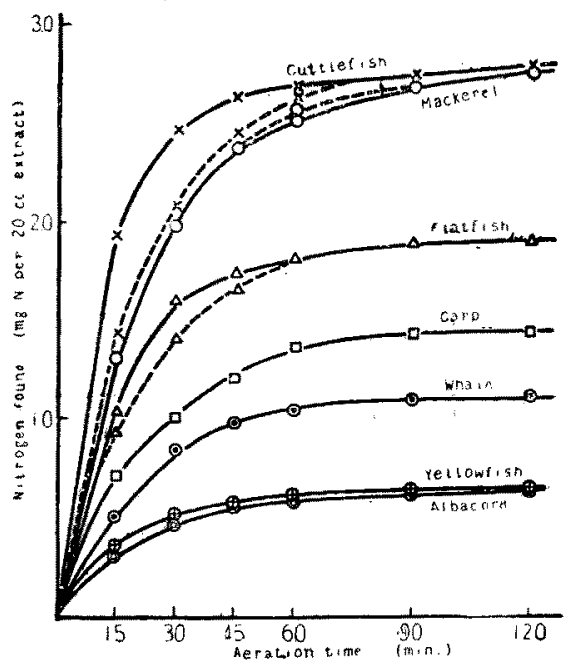

Fig. 2 Rate in removing the volatile base of spoiled fish meat

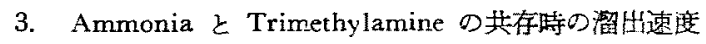

第2 報に括いて腐敗肉では，溜出初期の $K$ の値の大さいことは Trimethylamine によることを示唆し

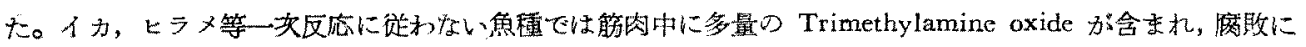

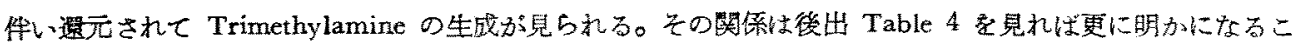
とと思う。ここては Ammonia と Trimethylamineが共存する時の溜出速度を調べるために, Ammonium chloride 液, Trimethylamine 液を作り, その両者を9:1 敒び 7:3になるよう混合した液を作り, 前と全 く同一条件で測定を行つた。このよろにして求めた溜出曲線よ Fig. 3 に更に算出した $K$ と $t$ の関保は

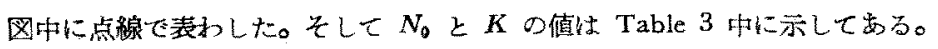

Table 3. The velocity constant in removing the volatile base (Mixed solution ef ammonium chloride and trimethylamine)

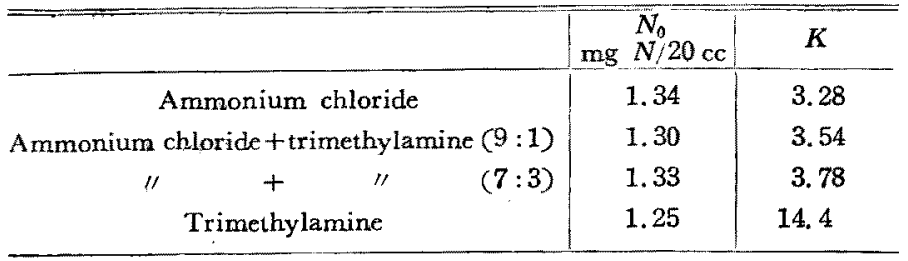

四より判るよらに Ammonium chloride $に$ Trimethylamine 学加交た本のでは初めに $K$ の大き店 Aminc 加溜出さ机可 ので大きな $K$ として表市れる, 特にこの㑯向は Amine の量加 増すにつれ鉴与藉しくなること 山確如られた。

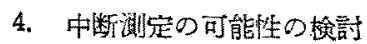




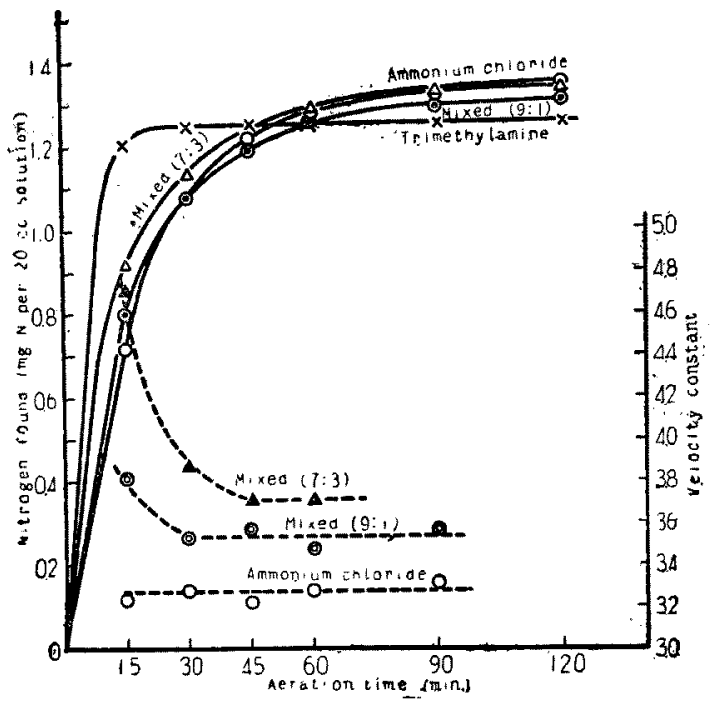

Fig. 3 Rate in removing the volatile base of the mixed solution of ammonium chloirde and trimethylamine Smooth line indicated the curves plotted againft nitrogen found, and broken line indicated the curves plotted against the velocity constant calculated.
1) 新焦時に含玉れる揮発性熄基の大部 分は Ammonia 化合物であるとは周知

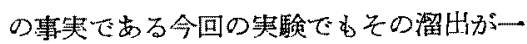
次反応に往い且魚種別の $K$ の差は殆どな いことが眀かにされた。従つて、このよう な場合には $50 \%$ 溜出に媳する洔間当当然 一定になる筈である。そこで Fig. 1，2に 示した結果より $N_{0} / 2$ (理論的 $50 \%$ 溜出 量) 求め, 且 $N_{0} / 2$ に要する時間 $\left(t_{1}\right)$ 老求めた結果が Table 4 に示してある。 その結果鮮魚では $t$ 等15 となり一定であ つた。央に $t=15$ 分に拁ける笑測值 $(N)$ と $N_{0} / 2$ とを比皎して見ると, Table 4 に 示したよらに良く一致することわ確められ た。それ故新鮮魚を対象とした場合には， 50\%溜出量学求める所謂中断測定が可能て あることが明かになつた訳で，15 分 $\left(t_{1}\right)$ の測定值を2 倍すれば所望の $N_{0}$ が得られ

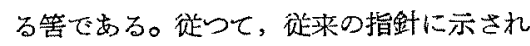
た装置及条件 $\left(45^{\circ} \mathrm{C}, 501 / \mathrm{hr}\right.$ ) ) て僅に 15 分閒に揮発性塩基の定量を実施することが 出来るよらになつた。

Table 4. 50 per sent removal of volatile base and trimethylamine and trimethylamine oxide contents in the fresh and spoiled fish meat of various species of $f$ ish

\begin{tabular}{|c|c|c|c|c|c|c|c|}
\hline Spectes & $\begin{array}{c}N_{9} \\
\text { Total vol. } \\
\text { basic } N \\
\text { content } \\
\text { mg\% }\end{array}$ & $\begin{array}{c}N_{0} / 2 \\
\text { Theoret. } \\
50 \% \text { re- } \\
\text { moval of } \\
\text { vol. base } \\
\text { mg } \% \\
\end{array}$ & $\begin{array}{c}t_{1} \\
\text { Time requ- } \\
\text { ired for } 50 \\
\% \text { removal } \\
\text { of vol. base } \\
\text { min. }\end{array}$ & $\begin{array}{l}50 \% \text { remo- } \\
\text { val of vol- } \\
\text { atile bace } \\
\text { (found aft- } \\
\text { er } 15 \mathrm{~min} \text {. } \\
\text { aerating) } \\
\text { mg } \%\end{array}$ & $\begin{array}{l}\text { Compared } \\
\text { with the- } \\
\text { oretical } \\
N_{0} / 2 \text { val- } \\
\text { ues } \\
\%\end{array}$ & $\begin{array}{l}\left(\mathrm{CH}_{3}\right) \mathrm{N} \\
\text { content } \\
\text { mg\% }\end{array}$ & $\begin{array}{c}\left(\mathrm{CH}_{3}\right)_{3} \mathrm{NO} \\
\text { content } \\
\text { mg\% }\end{array}$ \\
\hline $\begin{array}{l}\text { Fresh fish } \\
\text { carp } \\
\text { albacore } \\
\text { cuttle fish } \\
\text { yellowfish } \\
\text { (white muscle) } \\
\text { (dark muscle) } \\
\text { whale } \\
\text { flatfish } \\
\text { mackerel } \\
\text { Spoiled fish } \\
\text { carp } \\
\text { albacore } \\
\text { cuttlefi }{ }^{-} \\
\text {yellowfish } \\
\text { whale } \\
\text { flatfinh } \\
\text { mackert }\end{array}$ & $\begin{array}{r}10.0 \\
20.0 \\
12.3 \\
\\
14.6 \\
14.0 \\
30.1 \\
12.8 \\
20.8 \\
59.5 \\
29.7 \\
119.3 \\
30.9 \\
118 \\
186 \\
287\end{array}$ & $\begin{array}{c}5.0 \\
10.0 \\
6.15 \\
\\
7.3 \\
7.45 \\
15.0 \\
6.4 \\
10.4 \\
29.3 \\
14.9 \\
59.7 \\
15.5 \\
59 \\
93 \\
143.5\end{array}$ & $\begin{array}{l}15 \\
15 \\
15 \\
15 \\
15 \\
15 \\
15 \\
15 \\
15 \\
15 \\
11 \\
14.5 \\
15 \\
10.5 \\
16\end{array}$ & $\begin{array}{c}5.1 \\
10.1 \\
5.98 \\
\\
7.25 \\
7.30 \\
14.9 \\
6.6 \\
10.4 \\
29.5 \\
14.9 \\
81.5 \\
16.4 \\
59 \\
107 \\
132\end{array}$ & $\begin{array}{l}102 \\
101 \\
97.3 \\
\\
99.5 \\
98 \\
99.3 \\
103 \\
100 \\
\\
100.8 \\
100 \\
136.5 \\
113 \\
100 \\
115 \\
92.6\end{array}$ & $\begin{array}{l}0.61 \\
0.34 \\
1.70 \\
0.28 \\
1.61 \\
0.12 \\
0.15 \\
0.27 \\
\\
0.83 \\
2.38 \\
57.9 \\
2.83 \\
1.23 \\
60.7 \\
22.6\end{array}$ & $\begin{array}{c}1.26 \\
4.3 \\
94 \\
\\
18.0 \\
24.0 \\
0.3 \\
70 \sim 106 \\
10 \sim 22\end{array}$ \\
\hline
\end{tabular}


2）鮮店低下した魚ては魚種により溜出が必ずしも一次反応に往わないことがあることは既に述べたが， このようなるのに対して中断测定を行うことは困難であら5。そこをその原因の基となる㿥肉中の Trime-

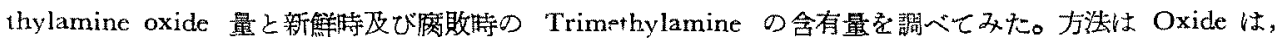
Devarda 合金で還元し次厄 picrate 法で比色する Dyer 沠5)で行い, 叉 Trimethylamine あ同じく Dyer の picrate 法匹行つた。その結果は, Table 4 の㕣側の欄に記载してある。イカ，ヒラメの上ろに多量の Trimethylamine oxide を含むむの山腐敗に当り著しく Amine 在形成するのて，中断測定に支障があるこ

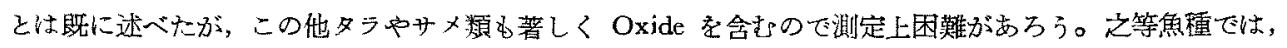

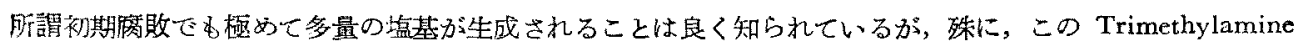

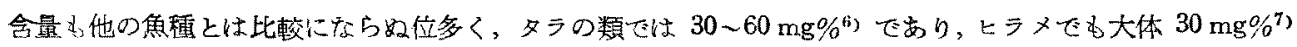
に当るので，恐らく，什断測定は不可能な魚瘇と云えよう。ブリ，サバの類も中等度の Oxide を含むが，

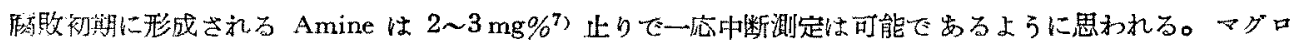

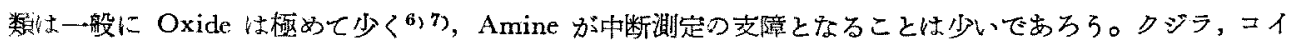

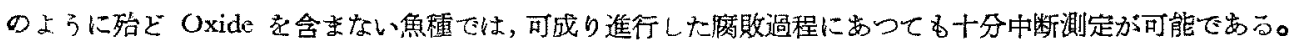

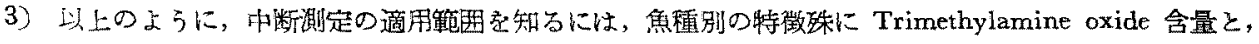

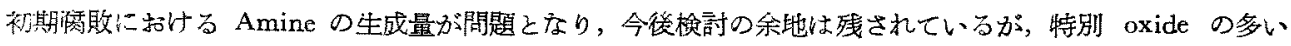

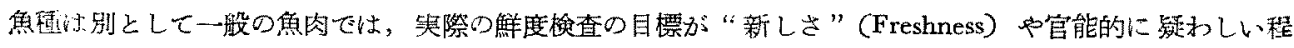

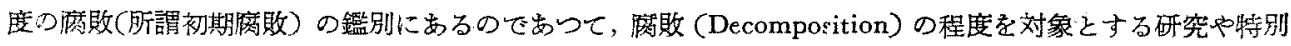
の場合を除いては，この中断測定は十分適用の可能性孝もち且極めて有効な方沠であるものと考点られる。

\section{むすび}

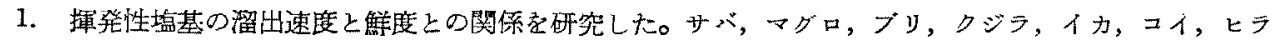
メについて調べた結果では新鮮の $K$ は一致し，その溜出は一头反応に良く徉ろことが判つた。穈敗肉つ $K$ は 45 分以降では一定であり且魚種別の羙む少かつたが，それ以前の初期溜出時のKはイカ，ヒラメて

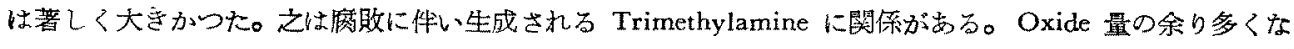
いブリ，サバでは，近似的に，極く少量か殆んど含まれていないマグロ，クジラ，コイ等では極めて良く一 次反流に㹥つた。

2. 以上の叓弗に基き著者は $50 \%$ 溜出量に基礎を扔く中断湘定考提唱した。則ち，指針に示された基本 条件 (装置, 温度, 通気量) 何等変更することなく，僅に 15 分間の通気により得られた溜出量る 2 倍す れば良いのである。但し，その対象とする焦種は，極く新鮮時には殆えど総てに邀用出来るようでむるが， 糜暊開始以後の魚肉では，イカタラ，ヒラメ、サメ等の上 $5 に$ Trimethylamine oxide 含量の高いものに は適用が困難であるよ5に思われた。

本研究に御指導を賜つた遠山蔽三博土に樑謝寸る。

\section{安献}

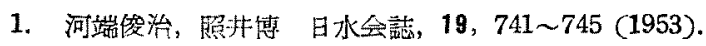

2. 富山哲夫, 原田悠三 日水会誌, 18, 112 116 (1952).

3. 河端俊治, 照扑尃 日水会誌，19，746 749 (1953).

4. 食品徫生㭘查指針 (增補及改訂沅) 1951 年厚生省編

5. W. J. Drer, F. E. Dyer \& J. M. Snow, J. Fish. Rer. Bd. Can., 8, 309-314 (1952).

6. W. J. Dyer, Ibid, 6, $351 \sim 358$ (1945).

7. W. J. Dyer, Ibid, 8, 31.4 -324 (1952).

8. 河端俊治 昭和 27 年秋季日水会大公趡演 